\title{
FERRAMENTAS DE MARKETING ONLINE UTILIZADAS NA UNIDADE DE INFORMAÇÃO DIGITAL DO SEBRAE/PB
}

\author{
Rosa Sylvana da Silva Mousinho
}

\section{Resumo}

Com o advento das Novas Tecnologias da Informação e Comunicação (NTIC) e a ampla utilização da Internet nas unidades de informação, surge a adoção do Marketing online, como instrumento de apoio para promoção de produtos e serviços em bibliotecas digitais. Nesse contexto, investiga a Biblioteca Digital do SEBRAE/PB quanto ao uso de ferramentas de marketing online utilizadas para promoção e divulgação de seus produtos e serviços na Internet. Identifica-se as ferramentas de marketing online utilizadas pela Biblioteca online SEBRAE/PB, descreve as ferramentas de marketing online existentes e verifica a atualização dessas ferramentas no site da biblioteca online SEBRAE. Propõe-se novas técnicas de marketing online para a aplicação em Biblioteca Digital. Tem como abordagem metodológica um estudo qualitativo e informações coletadas realizadas através da observação do site da Biblioteca online SEBRAE. Os resultados apontam para a aplicação e uso das ferramentas de marketing online. Confirma o fato de que o marketing online surge como uma ferramenta de estímulo entre as organizações e seus usuários no que se refere a demanda de serviços e produtos informacionais, utilizando a interatividade e tendo como o principal diferencial o uso da tecnologia. Fortalece a afirmação que o profissional que trabalhe nesta área deva conhecer as estratégias de marketing que pode utilizar para tornar as relações com seus usuários mais produtivas e efetivas. Contribui para a disseminação, análise e futuras implantações de outras ou novas ferramentas de marketing online nas unidades de informação digitais, buscando compreender o papel do bibliotecário em sua busca de satisfazer os usuários, agora, também, por meio do uso de novas ferramentas nesse novo ambiente que é o ciberespaço.

Palavras-chave: Marketing online - SEBRAE/PB. Unidades de informação. Biblioteca digital SEBRAE/PB. Ferramentas de Marketing. Internet.

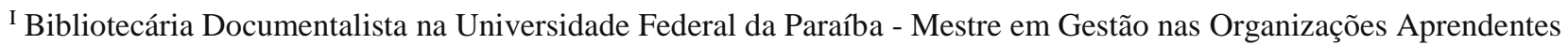
pela Universidade Federal da Paraíba - email: syllmouser@ hotmail.com
} 